\title{
PENGARUH TERPAAN IKLAN DAN BRAND LOYALTY TERHADAP MINAT BELI PRODUK SAMSUNG GALAXY
}

\author{
Dionisius Aditya Yoganata \\ Fakultas Ilmu Komunikasi, Universitas Gunadarma \\ email: dionisiusay@student.gunadarma.ac.id
}

\begin{abstract}
The purpose of this research is to find out whether exposure to advertising and brand loyalty influences buying interest of Samsung Galaxy products. The theory used in this study is the AIDA model (Attention, Interest, Desire, Action), and the Advertising Exposure Process proposed by David. A Aaker. The research method used by the authors in this study is a quantitative method approach. The objects in this study are those who want to make purchases of Samsung Galaxy products, as well as those who have already used Samsung Galaxy products, which are determined by 85 respondents of the study sample. This research is quantitative descriptive, where the primary data collected through questionnaires are processed statistically, so that the measurement scale. The results of this study indicate that the variable exposure to advertising has an influence on buying interest of Samsung Galaxy by 46.6 percent. Also, the brand variable variable has an influence on buying interest of Samsung Galaxy products by 48.4 percent. Also, the variable exposure to advertising and brand loyalty has an influence on buying interest of Samsung Galaxy products by 61.8 percent together. Meanwhile, the rest is influenced by other variables not examined in this study. The conclusion of this study shows that there is an influence between exposure to advertising and brand loyalty on the purchase interest of Samsung Galaxy products, both partially and simultaneously. Suggestions from this study that the author can provide include further research of a similar nature in order to use other variables not contained in this study. Also, it is hoped that this research can be used as a reference, both for producers and those who should be consumers.
\end{abstract}

Keyword: exposure; brand loyalt;, interest in buying products.

\begin{abstract}
ABSTRAK
Tujuan Penelitian ini untuk mengetahui apakah terpaan iklan dan brand loyalty mempengaruhi minat beli produk Samsung Galaxy. Teori yang digunakan dalam penelitian ini adalah model AIDA (Attention, Interest, Desire, Action), serta Advertising Exposure Process yang dikemukakan oleh David. A. Aaker. Metode Penelitian yang digunakan oleh penulis dalam penelitian ini adalah pendekatan metode kuantitatif. Objek dalam penelitian ini adalah mereka yang hendak melakukan pembelian terhadap produk Samsung Galaxy, maupun mereka yang sudah pernah menggunakan produk Samsung Galaxy, yang ditentukan sebanyak 85 responden sampel penelitian. Penelitian ini bersifat kuantitatif deskriptif, dimana data primer yang dikumpulkan melalui penyebaran kuesioner diolah secara statistik, sehingga berbentuk skala pengukuran. Hasil penelitian ini menunjukan bahwa variabel terpaan iklan memiliki pengaruh terhadap minat beli Samsung Galaxy sebesar 46,6 persen. Dan juga, variabel brand loyaty memiliki pengaruh terhadap minat beli produk Samsung Galaxy sebesar 48,4 persen. Serta, variabel terpaan iklan dan brand loyalty memiliki pengaruh terhadap minat beli produk Samsung Galaxy sebesar 61,8 persen secara
\end{abstract}


bersama-sama. Sedangkan, sisanya dipengaruhi oleh variabel-variabel lainnya yang tidak diteliti dalam penelitian ini. Kesimpulan dari penelitian ini menunjukan bahwa terdapat pengaruh antara terpaan iklan dan brand loyalty terhadap minat beli produk Samsung Galaxy, baik itu secara simultan maupun secara parsial. Saran dari penelitian ini yang dapat penulis berikan antara lain penelitian selanjutnya yang bersifat sejenis agar menggunakan variabel lainnya yang tidak terdapat dalam penelitian ini. Serta, diharapkan penelitian ini dapat dijadikan acuan, baik itu untuk pihak produsen maupun mereka yang hendaknya menjadi konsumen.

Kata Kunci: brand loyalty; minat beli produk; terpaan.

\section{PENDAHULUAN}

Minat beli konsumen pada dasarnya merupakan faktor pendorong dalam pengambilaan keputusan pembelian terhadap suatu produk. Menurut Yamit (2005) minat beli konsumen merupakan evaluasi purna beli atau hasil evaluasi setelah membandingkan apa yang dirasakan dengan harapannya. Menurut Durianto (2004) minat beli merupakan sesuatu yang berhubungan dengan rencana konsumen untuk membeli produk tertentu, serta berapa banyak unit produk yang dibutuhkan pada periode tertentu.

Tingkat minat beli yang tinggi dapat dipengaruhi oleh adanya terpaan iklan yang terus menerus dikonsumsi oleh masyarakat (Alfan, 2010). Hal ini pun sesuai dengan teori Advertising Exposure Process yang dikemukakan oleh David A. Aaker yang mengemukakan bahwa apabila konsumen terkena terpaan iklan maka akan tercipta perasaan dan sikap tertentu terhadap merek yang kemudian akan menggerakan konsumen untuk membeli produk (Nurbani, 2016).

Aaker (1996) menyatakan bahwa terpaan sebuah iklan sebagai variabel independen dapat diukur melalui tiga dimensi, yaitu dimensi frekuensi, dimensi durasi dan dimensi intensitas. Terpaan ditentukan dari frekuensi (seberapa sering iklan dilihat dan dibaca), intensitas (seberapa jauh khalayak mengerti pesan dalam iklan), dan durasi (seberapa lama khalayak memperhatikan iklan). Sesering dan selama apapun seseorang melihat sebuah iklan, belum tentu ia akan melihat iklan tersebut dengan seksama (dari awal sampai akhir), sehingga bisa saja hanya sekilas maupun sebagian.

Kurniawan (2012) mengatakan bahwa brand loyalty berpengaruh dalam menimbulkan minat beli konsumen. Brand loyalty (loyalitas merek) sendiri merupakan suatu ukuran keterkaitan pelanggan kepada sebuah merek (Durianto, 2001). Dharmmesta (1999) mendefinisikan loyalitas merek merupakan respon perilaku yang bersifat bias, terungkap secara terus menerus oleh unit pengambilan keputusan dengan memperhatikan suatu atau beberapa alternatif dari sejumlah merek sejenis dan merupakan fungsi psikologis. Dharmmesta mencontohkan loyalitas sebuah merek yang rentan terhadap perbedaan harga atau terhadap kondisi kehabisan persediaan memerlukan perhatian yang lebih besar.

Kurniawan (2012) menyatakan bahwa variabel brand loyalty merupakan variabel yang paling berpengaruh terhadap minat beli dibandingkan variabel-variabel lainnya. Menurut Mowen (1995) ia menyatakan bahwa loyalitas merek didefinisikan sebagai tingkatan dimana pelanggan memiliki sikap positif terhadap suatu merek, memiliki komitmen dan cenderung untuk terus melanjutkan membeli produk dengan suatu merek tertentu dimasa yang akan datang.

Damayanti (2007) menyatakan 93 \% konsumen Indonesia termasuk recreational shoppers (pembelanja rekreasi) dimana mereka berbelanja bukan karena kebutuhan, 
tetapi lebih untuk kesenangan. Dikutip dari laman Counterpoint Research yang dirilis pada Februari 2019, produk Samsung memimpin pasar smartphone dalam kategori delivery smartphone berdasarkan merek. Penelitian dilakukan berdasarkan data delivery smartphone secara global selama delapan tahun kebelakang.

Lembaga riset International Data Corporation (IDC) juga merilis data yang menunjukan daftar lima merek smartphone terlaris di Indonesia selama kuartal kedua 2018. Dalam daftar tersebut, didapati brand Samsung menduduki peringkat pertama dengan pangsa pasar sebesar 27 persen. Produk Samsung ini sendiri mulai berdiri di Indonesia pada pertengahan April tahun 2009 lalu. Maka dari itu, tidak heran jika Samsung menjadi salah satu produk smartphone yang dikenal oleh banyak kalangan di Indonesia.

Damayanti (2007) menyatakan bahwa mahasiwa adalah kelompok yang berorientasi konsumtif, karena kelompok ini suka mencoba hal-hal baru dan bermerek, mahasiswa akan cenderung meniru mode-mode baru. Suatu merek yang dapat memberikan nilai positif dan diterima oleh kelompok sosial di sekitar konsumen akan mempengaruhi konsumen untuk membayar dengan harga maksimum bagi suatu merek dan hal tersebut dapat dikatakan sebagai bentuk dari brand loyalty (Maukar, 2013).

Hasil penelitian Rombe (2014) menyatakan bahwa untuk mendukung kepercayaan diri yang dimiliki, khususnya oleh remaja putri dalam hal penampilan dirinya, maka remaja putri akan berusaha untuk menjaga penampilan dan mempertahankan kepercayaan dirinya dengan selalu mengikuti dan berusaha memiliki barang-barang yang sedang trend serta akan berusaha untuk mendapatkannya, sehingga dapat menyebabkan pembentukan pola prilaku konsumtif.

Akhirnya, peneliti memilih mahasiswa angkatan 2015 sebagai subjek penelitian. Hal ini didasari karena mahasiswa termasuk dalam kategori yang sesuai dengan penjelasan sebelumnya. Dan juga, hal yang menjadi salah satu pertimbangan adalah karena mereka memiliki pengetahuan dan informasi yang cukup mengenai produk Samsung Galaxy. Karenanya, mahasiswa S1 FIKOM Universitas Gunadarma angkatan 2015 dipilih sebagai responden untuk mewakili penelitian terhadap minat beli produk Samsung Galaxy dikalangan mahasiswa.

Maka, dengan latar belakang yang telah diuraikan diatas, peneliti pun ingin mengetahui pengaruh sebuah iklan dan brand loyalty seseorang sehingga akhirnya ia memilih untuk membeli sebuah produk dari Samsung. Akhirnya, peneliti pun merasa tertarik untuk melakukan penelitian melalui latar belakang diatas dengan judul "Pengaruh Terpaan Iklan dan Brand Loyaty terhadap Minat Beli Produk Samsung Galaxy".

\section{METODE}

Metode dalam penelitian ini menggunakan teknik pendekatan kuantitatif, dikarenakan data-data yang diambil berbentuk angka-angka yang selanjutnya akan diolah secara statistik. Dengan penelitian yang bersifat kuantitatif deskriptif, proses pengumpulan data primer akan dilakukan melalui penyebaran kuesioner, yang dibentuk dalam skala pengukuran. Hal ini nantinya juga didukung dengan beberapa data maupun dokumen dari berbagai jurnal yang dapat digunakan sebagai refrensi dalam penelitian ini. Dalam proses penyebaran data, peneliti menggunakan google form sebagai media penyebarannya. Kuesioner elektronik inilah yang nantinya akan disebar kepada para responden penelitian. Pada pengambilan sampel penelitian menggunakan teknik Convenience Sampling, yang dimana peneliti dapat memilih anggota populasi yang mempunyai data serta mudah diperoleh. 


\section{HASIL DAN PEMBAHASAN}

Berdasarkan hasil dari penelitian dan perhitungan diatas, selanjutnya diolah untuk disimpulkan bahwa:

1. Pada hasil uji validitas disetiap masing-masing variabel, yaitu terpaan iklan dan brand loyalty (variabel independen) terhadap minat beli (variabel dependen) dapat dikatakan bahwa dari seluruh item pernyataan penelitian dinyatakan valid. Hal ini dikarenakan seluruh nilai korelasi $R$ hitung lebih besar dari $R$ tabel $(>0,3061)$. Ini berarti, setelah dilakukan uji validitas terhadap sampel penelitian, menunjukan bahwa pernyataan telah layak digunakan untuk tahap penelitian selanjutnya.

2. Pada hasil uji reliabilitas menunjukan bahwa besarnya nilai Alpha Cronbach dari variabel terpaan iklan adalah sebesar 0,828. Kemudian pada variabel brand loyalty sebesar 0,879. Serta, pada variabel minat beli sebesar 0,832. Sehingga, dapat disimpulkan bahwa setelah dilakukan uji reliabilitas terhadap sampel penelitian, hal ini menunjukan bahwa seluruh pernyataan memiliki reliabilitas yang baik dan reliabel. Serta, pernyataan tersebut seluruhnya dapat digunakan untuk tahap penelitian selanjutnya.

3. Dalam penelitian ini dapat diketahui bahwa terpaan iklan dan brand loyalty ternyata memiliki pengaruh terhadap minat beli produk Samsung Galaxy. Kedua variabel tersebut dapat mempengaruhi minat beli seseorang terhadap produk Samsung Galaxy, baik itu secara parsial maupun secara simultan.

4. Dari hasil penelitian yang penulis buat, ditemukan beberapa poin penting. Pertama, diketahui bahwa secara parsial, variabel terpaan iklan memiliki pengaruh sebesar 46,6 persen terhadap minat beli Samsung Galaxy. Serta, variabel brand loyaty memiliki pengaruh sebesar 48,4 persen terhadap minat beli produk Samsung Galaxy. Sedangkan sisanya, dipengaruhi oleh variabel-variabel bebas lainnya yang tidak diteliti dalam penelitian ini. Dari hal ini dapat diketahui, bahwa variabel brand loyalty memiliki pengaruh yang lebih besar terhadap minat beli produk Samsung Galaxy dibanding variabel terpaan iklan, walaupun memang tipis perbedaannya. Kemudian, apabila dilihat secara simultan variabel terpaan iklan dan brand loyalty memiliki pengaruh sebesar 61,8 persen terhadap minat beli produk Samsung Galaxy. Sedangkan, sisanya yaitu $38,2 \%$ dipengaruhi oleh variabel-variabel lain yang tidak diteliti dalam penelitian ini.

5. Dalam penelitian ini terdapat teori New Media, dimana media baru muncul akibat inovasi teknologi dalam bidang media meliputi televisi kabel, satelit, teknologi optic fiber dan komputer. Dengan teknologi tersebut, para pengguna dapat secara aktif dalam membuat pilihan serta menyampaikan respon produk yang ditawarkan secara beragam. Dalam penelitian ini juga menggunakan teori Advertising Exposure Process, dimana khalayak berperan aktif dalam menyaring dan mengolah segala informasi yang diterimanya, dari berbagai bentuk media informasi yang beragam. Secara garis besar, peneliti ingin mengetahui adakah pengaruh, baik itu terpaan iklan maupun brand loyalty terhadap minat beli produk Samsung Galaxy. Dari penelitian diatas pun dapat diketahui bahwa setiap audiens akan menggunakan produk yang sesuai untuk memenuhi kebutuhannya. Karena kebutuhannya tersebut harus terpenuhi, maka audiens mencoba untuk mencari tahu lebih dalam terkait produk yang akan dia butuhkan tersebut. Apabila sudah teercapai tahap pembelian, dan audiens merasa puas dengan produk yang ditawarkan, maka akan ada kemungkinan untuk terjadi proses pembelian ulang. Kemudian, jika proses tersebut terjadi secara terus menerus, maka audiens tersebut sudah dapat dikatakan mencapai tahap brand loyalty (kecintaan akan suatu produk). 


\section{KESIMPULAN}

Berdasarkan hasil penelitian di bab sebelumnya mengenai minat beli produk Samsung Galaxy yang dipengaruhi oleh terpaan iklan dan brand loyalty, maka sesuai dengan tujuan penelitian diawal, penulis dapat menyimpulkan bahwa:

1. Terdapat pengaruh antara terpaan iklan terhadap minat beli produk Samsung Galaxy, dengan nilai persentase sebesar 46,6\%.

2. Terdapat pengaruh antara brand loyalty terhadap minat beli produk Samsung Galaxy, dengan nilai persentase sebesar 48,4\%.

3. Terdapat pengaruh antara terpaan iklan dan brand loyalty terhadap minat beli produk Samsung Galaxy, dengan nilai persentase sebesar 61,8\%.

Setelah melakukan penelitian dengan metode yang ada, penulis menarik kesimpulan bahwa terpaan iklan dan brand loyalty ternyata memiliki pengaruh terhadap minat beli produk Samsung Galaxy. Kedua variabel tersebut dapat mempengaruhi minat beli seseorang terhadap produk Samsung Galaxy, baik itu secara parsial maupun secara simultan.

Kemudian, apabila kita ingin melihat, manakah diantara variabel terpaan iklan maupun brand loyalty, yang lebih berpengaruh terhadap minat beli produk Samsung Galaxy tersebut, maka kita harus melihatnya secara parsial. Dari penjelasan diatas sebelumnya telah diketahui bahwa variabel terpaan iklan memiliki pengaruh sebesar 46,6 persen terhadap minat beli Samsung Galaxy. Sedangkan, variabel brand loyaty memiliki pengaruh sebesar 48,4 persen terhadap minat beli produk Samsung Galaxy. Hal ini menunjukan, bahwa variabel brand loyalty memiliki pengaruh yang lebih besar terhadap minat beli produk Samsung Galaxy dibanding variabel terpaan iklan, walaupun tipis perbedaannya. Sedangkan, apabila dilihat secara simultan variabel terpaan iklan dan brand loyalty memiliki pengaruh sebesar 61,8 persen terhadap minat beli produk Samsung Galaxy. Nilai ini terlihat cenderung lebih besar apabila dibandingkan dengan nilai yang dihitung secara parsial. Hal ini dikarenakan, variabel minat beli tersebut dipengaruhi oleh variabel terpaan iklan dan brand loyaty secara bersama-sama, sehingga besaran pengaruhnya akan lebih besar dibandingkan dengan apabila hanya dipengaruhi oleh salah satu variabel bebas diatas.

\section{DAFTAR RUJUKAN}

\section{Buku}

Bungin, Burhan (2011) Konstruksi Sosial Media Massa. Jakarta: Kencana

Cresswll, J. W. (2010) Research Design: Pendekatan Kualitatif, Kuantitatif, dan Mixed.

Yogyakarta: PT Pustaka Pelajar.

Croteau, D. dan Hoynes W. (1997) Media Society: Industries, Images, and Audiences. New Delhi: Pine Forge Press.

Danandjaja. (2011) Peranan Humas Dalam Perusahaan. Cetakan Pertama. Yogyakarta: Graha Ilmu.

Efendi, Onong Uchjana (1984) Ilmu Komunikasi Teori dan Praktek. Bandung: RosdaKarya.

Hawkins, D., Best R. J. dan Coney (1986) Consumer Behavior: Implications For Marketing Strategy (3th Ed). Homewood: Illnois Business Publication, Inc.

Indriantoro, N. dan Supomo, Bambang (2013) Metodologi Penelitian Bisnis untuk Akuntansi dan Manajemen. Yogyakarta: BPFFE.

Joseph A. Devito, (2010) Komunikasi Antarmanusia, Karisma Publishing.

Kotler. P., Bowen J. dan Makens J. (1999) Marketing for Hospitally and Tourism (Internation Ed). New Jersey: Prentice Hall.

Liliweri, Alo (2011) Komunikasi Serba Ada Serba Makna. Jakarta: Prenada Media Group. 
McQuail, Dennis (2000) Teori Komunikasi Massa, Suatu Pengantar. Jakarta: Erlangga. Nurbenny (2005) Model-Model Komunikasi Pemasaran. Bandung: Rosdakarya.

Nurudin (2007) Pengantar Komunikasi Massa. Jakarta: Raja Grafindo Persada.

Pavlik, John V. (1998) New Media Technology: Cultural and Commercial Perspective, Boston: Allyn and Bacon.

Santosa, Sigit (2009) Creative Advertising. Jakarta: Elex Media Komputindo.

Schoffman dan Kanuk (2004) Perilaku Konsumen Edisi 7. Jakarta: Prentice Hall.

Sugiyono (2009) Metode Penelitian Kuantitatif, Kualitatif dan R\&D. Bandung: Alfabeta.

Sugiyono (2012) Metode Penelitian Kuantitatif, Kualitatif dan R\&D. Bandung: Alfabeta.

Sugiyono (2013) Metode Penelitian Pendidikan Pendekatan Kuantitatif, Kualitatif dan R\&D. Bandung: Alfabeta.

Swastha, B. dan Irawan (2001) Manajemen Pemasaran Modern. Yogyakarta: Liberty.

Tjiptono, Fandy (2010) Pemasaran Jasa, Prinsip, Penerapan, dan Penelitian. Yogyakarta: Andi Offset.

Wells, Wiliam, John Burnett, Sandra Moriarty (1995) Advertising: Principles and Practice 3th Edition: Prentice Hall.

\section{Jurnal}

Alfan, Bakhtiar (2010) Pengaruh Terpaan Iklan Spanduk Rokok Bintang Buana Terhadap Minat Beli (Pada Masyarakat Gaten, Dabag, Condongcatur, Depok, Sleman).

Batra R, Myers J. G., Aaker, D. A. (1996) Advertising Management $5^{\text {th }}$ Edition Prentice Hall International Edition: New Jersey.

Damayanti, T. dan Abdul H. (2007) Pengelolaan Keuangan Daerah Edisi Kedua: Yogyakarta.

Desi Arista dan Sri Rahayu Triastuti (2011) Pengaruh Iklan Merek, Kepercayaan Merek dan Citra Merek terhadap Minat Beli Konsumen, Semarang.

Dharmmesta, B. S. (1999) Loyalitas Pelanggan: Sebuah Kajian Konseptual Sebagai Panduan Bagi Penelitian: Jurnal Ekonomi dan Bisnis Indonesia.

Durianto, Darmadi (2001) Strategi Menaklukan Pasar Melalui Riset Ekuitas dan Perilaku Merek, Jakarta.

Durianto D. dan C. Liana (2004) Analisis Efektivitas Iklan Televisi Softener Soft \& Fresh di Jakarta dan Sekitarnya dengan Menggunakan Consumen Decision Model, Jurnal Ekonomi Perusahaan.

Ghozali, Imam (2012) Aplikasi Analisis Multivariate dengan Program IBM SPSS. Yogyakarta: Universitas Diponegoro.

Giddens, Nancy (2002) Brand Loyalty. Missouri Value-added Development Center, University of Missouri.

Haryanto, J. O. dan Anggie C. (2011) Analysis of The Effect of Olfactory, Approach Behavior, and Experiental Marketing. Gadjah Mada International Journal of Business.

Hidayat (2016) Pengaruh Konsep Diri dan Kepercayaan Diri terhadap Perilaku Konusmtif Pembelian Gadget pada Mahasiswa Fakultas Hukum Non Reguler Universitas Islam Riau: Riau.

Kurnia. (2005) Perkembangan Teknologi Komunikasi dan Media Baru, Implikasi terhadap Teori Komunikasi.

Kurniawan (2011) Analisis Pengaruh Brand Loyalty, Brand Image, Iklan dan Perceived Quality terhadap Minat Beli Konsumen XL Prabayar di kota Surabaya, Surabaya.

Lidyawatie (1998) Hubungan Antara Intensitas Menonton Iklan di Televisi dengan Perilaku Konsumtif. Surakarta: Fakultas Psikologis UMS.

Maukar, Desy Christian (2013) Hubungan Konformitas Remaja dan Identitas Sosial dengan Brand Loyalty pada Merek Starbucks Coffe Surabaya, Surabaya. 
Mowen (1995) Brand Loyalty Loyalitas Merek, Jurnal Kajian Bisnis Oktober.

Nurbani (2016) Pengaruh Terpaaan Iklan E-Commerce Bukalapak di Televisi Terhadap Perilaku Konsumtif di Kalangan Mahasiswa Fakultas Ekonomi dan Bisnis UIN Syarif Hidayatullah Jakarta, Jakarta.

Pratama (2017) Hubungan Konformitas dengan Perilaku Konsumtif terhadap Merchandise Liverpool pada Anggota Suporter Klub Sepkabola Liverpool di Bekasi, Depok.

Rombe (2014) Hubungan Body Image dan Kepercayaan Diri dengan Perilaku Konsumtif pada Remaja Putri di SMA Negeri 5 Samarinda, Samarinda.

Winarni (2015) Pengaruh Citra Merek dan Terpaan Iklan terhadap Keputusan Pembelian Toyota Yaris di Kota Semarang, Fakultas Ilmu Komunikasi Universitas Diponegoro, Semarang.

Yamit, Zulian (2005) Manajemen Kualitas Produk dan Jasa, Yogyakarta.

\section{Internet}

https://teknologi.bisnis.com/read/20180201/101/733037/pengguna-perangkat mobiledi-indonesia-semakin-tinggi-ini-datanya (Senin, 25 Maret 2019 : 17.05)

https://www.counterpointresearch.com/global-smartphone-shipments-share-lasteightyears-of-winners-losers (Senin, 25 Maret 2019 : 16.58)

https://kumparan.com/@kumparantech/5-merek-smartphone-terlaris-di-indonesiaselama-kuartal-kedua-2018-1536377970835236526 (Senin, 25 Maret 2019 : 17.15).

https://i1.wp.com/isparmo.web.id/wpcontent/uploads/2018/08/berdasar_usia_data pengguna_internet_Indonesia_2017_APJII.png (Senin, 25 Maret $2019: 00.14$ )

http://www.pendidikanekonomi.com/2012/10/pengertian-keputusan-pembelian konsumen.html (Sabtu, 30 Maret 2019 : 14.58)

http://jurnal-sdm.blogspot.com/2009/10/brand-loyalty-loyalitas-merek-definisi.html (Sabtu, 30 Maret 2019 : 20.51)

https://www.samsung.com/id/home-appliances/ (Sabtu, 22 Maret 2019 : 22.55)

http://epthealwayz.blogspot.com/2013/01/teori-teori-media-massa.html (Minggu, 31 Maret 2019 : 13.34)

https://hneeson.weebly.com/blog/strong-and-weak-theories-of-advertising (Minggu, 31 Maret 2019 : 13.45)

http://adityolaksono26.blogspot.com/2015/03/pengertian-minat-beli-dan-faktor faktor.html (Senin, 29 April $2019: 17.02)$

http://tutorialkuliah.blogspot.com/2009/11/teori-keputusan-pembelian-aida.html (Senin, 29 April 2019 : 17.09) 